and $a$ third section on miscellaneous methods, including dipole moments and nuclear magnetic resonance. The approach is theoretical rather than practical but care is taken to indicate the types of information that can be obtained by the application of the methods discussed. A.t the end of each chapter are useful references to more extensive publications on the subjects under discussion.

J. W. Cook

\section{GENETICS OF CONTINUOUS VARIATION}

Introduction to Quantitative Genetics

By D. S. Falconer. Pp. ix +365 . (Edinburgh and London: Oliver and Boyd, Ltd., 1960.) 35s. net.

71

HE genetical study of continuous variation has

had a somewhat chequered career. To Darwin this was the variation that mattered above all, and it was the variation to which Galton and later Pearson devoted their unsuccessful efforts to work out the principles of herodity. To the early Mendelians, however, it was, one feels, a puzzle and even a nuisance, intractable by their techniques and a source of acid dispute. True, the basis for understanding its determination and properties was laid down during this period; but its experimental study was so much more tedious and its theory so much more mathematical that for several decades it just failed to hold its interest in the face of the more classical type of genetical study. Now the situation has changed again. The significance of continuous variation in wild populations and its key importance for plant and animal breeding are fully recognized, and the past fifteen years or so have seen a tremendous growth in its genetic study. Its problems and perhaps even more its analytical techniques may still set it apart as a somewhat specialized branch of genetics, but it is as essential to an appreciation of the science at one end as cell chemistry, deoxyribonucleic acid and gene structure are at the other.

Dr. Falconer has now given us a text-book of, as he terms it, "Quantitative Genetics", and we are indebted to him for it. It is a noteworthy book in several ways. To most biologists it will read more like a text-book of physics than like the type of biological literature with which they are familiar, so much is mathematics an integral part of the structure. Yet we should be grateful that the mathematics is never oppressively advanced or complex - a virtue which will be acknowledged the more readily by those who have attempted other texts in this field. Within its ambit it covers the ground admirably, and its length serves only to indicate the amount of ground to be covered. The behaviour of genes in populations, variation, heritability, selection, inbreeding and heterosis, particularly as they appear in animal experiments, are all dealt with lucidly as well as carefully : indeed in places, as where family selection is analysed and discussed, the treatment is of a notably high order. Occasionally a laxness of expression creeps in, as where it is said that the "partition of (phenotypic) variance into genotypic and environmental components formulates the problem of ... the relative importance of genotype and environment in determining the phenotypic value"surely one of the oldest non-sequitur in the history of genetics. At times, too, the argument is more than a little tendentious; but these periodical blemishes can weigh only lightly in the balance against the generally consistent quality of the book.

The risk of a book such as "Quantitative Geneties" lies elsewhere, in its very success in presenting the mathematically analytical approach. Mathematics has a charm of its own, in the clarity, generality and finality with which its conclusions emerge. These, however, can never be sounder than the evidence, postulates and concepts from which they are derived, and the charm becomes meretricious if it blinds us to the limitations of the situations, the complexities of the relations or the uncertainty of the premisses we are exploring. Dr. Falconer, for example, spends little time on linkage: he largely contents himself with reiterating the charge that mathematies has shown it cannot have much importance in relation to selection while ignoring the exporimental evidence that it is in fact not so lightly to be dismissed. He discusses correlated response to selection wholly in terms of pleiotropy, which is easy to handle by correlation technique, but overlooks the cases where linkage supplies, to say the least, a much more satisfactory interpretation of the experimental results. $\mathrm{H} \Theta$ argues for a simple relation between heterozygosity and fitness but barely mentions the self-fertilizing plants which show that this relation must itself be the product of natural selection in the past. He states that the genes governing number of bristles in Drosophila show no dominance, and bolsters his contention that this character is selectively neutral by postulating hypothetical pleiotropic effects of these genes while supporting his view by reference to evidence which is at least as readily interpretable in the opposite way. In justice to Dr. Falconer it must be said that most of these opinions are to be found in the final chapter, which he himself describes as setting out his own views on controversial topics. This is a praiseworthy warning, for indeed whatever disagreement we may feel with these final sections should never be allowed to blind us to the great value of the other nine-tenths of the book, or to the debt we owe Dr. Falconer for so ably presenting the subject, especially as it appears to the animal geneticist, for the benefit of all our students. Kenneth Mathek

\section{THE YELLOW FEVER MOSQUITO}

\section{Aëdes aegypti (L)}

The Yellow Fever Mosquito-Its Life History. Bionomics and Structure. By Sir S. Rickard Christophers. Pp. xii +739. (Cambridge : At the University Press, 1960.) 75s. net.

$7 \mathrm{HE}$ yellow fever mosquito is a most appropriate subject for a large treatise. Of all mosquitoes it is that most easily maintained in culture in the laboratory. Its most characteristic breeding site is the small tree-hole containing an ounce or two of water, very liable to dry up. The eggs stranded under these conditions can withstand desiccation for many months and hatch in a few minutes when immersed in water; abundantly fed, they reach the adult state in a few days. It is therefore a most valuable experimental animal upon which much of our knowledge of the physiology of mosquitoes in general has been based. It has been extensively used as a test object for insecticides and repellents.

Few insects have suffered more at the hands of taxonomists than this mosquito. It is now generally known as Aëdes aegypti Linnous 1762. It may or 